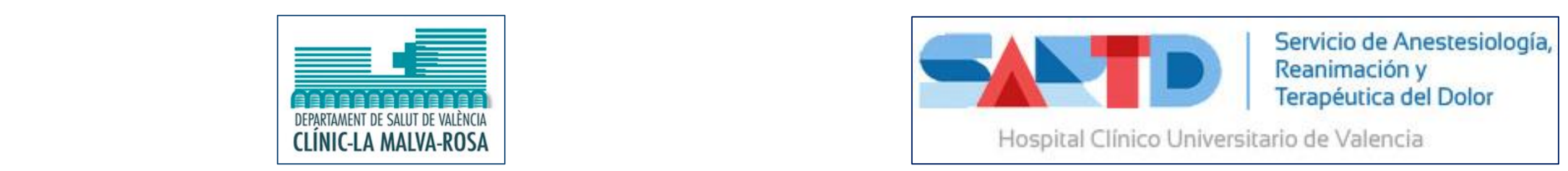

\title{
Accidental subdural catheterization after epidural technique for analgesia during labor. About a case.
}

Martínez-Castro S, Escamilla B, Sancho L, Herrera R, Tornero C.

Department of Anesthesia and Critical Care. Hospital Clínic Universitari, València (Spain)

BACKGROUND Among the complications of the epidural technique there is the subdural blockade (SB) and cannulation of the subdural space $^{1-2}$, with a prevalence of $0.024 \%$. The SB has a low diagnostic rate, usually retrospective. Therefore, we should have it in mind. We present the case of a woman with SB who gave birth without problems and had definitive radiological diagnosis after clinical suspicion.

CASE REPORT 32 year old woman in labor requesting epidural analgesia. Previous vaginal delivery without incidences. Anesthesiologist performed a single atraumatic puncture with Tuohy $18 \mathrm{G}$ needle, administering test dose with $3 \mathrm{ml}$ of $0.25 \%$ bupivacaine with vasoconstrictor; any hemodynamic nor blockade response. A bolus of $10 \mathrm{ml}$ of $0.125 \%$ Levobupivacaine $9 \mathrm{ml}+50 \mathrm{mcg}$ of fentanyl $(1 \mathrm{ml})$ is administered later. On physical examination after the dose: paralysis of both legs, mobility preserved in upper limbs, pain and temperature abolished to sternal level. No perfusion is connected to catheter nor new boluses of local anesthetic are administered. Painless childbirth. The patient recovers mobility in lower limbs just after labor and no headache appears on successive days. X-ray image shows the definite diagnosis ("railroad rails") $3-4$.

\section{COMPLICATIONS AFTER PERIDURAL BLOCKADE \\ - Dural puncture, \\ - Intravascular injection (overdosage of local anesthetic (LA)), \\ - Subarachnoid injection of LA, \\ - Complications related to catheter: insertion in the epidural vein, placement in the subarachnoid space, cannulation of the subdural space; \\ - Direct trauma of the spinal cord, \\ - Epidural abscess \\ - Epidural hematoma, \\ - Meningitis, \\ - Subdural blockade.}

\section{RELEVANT INFORMATION}

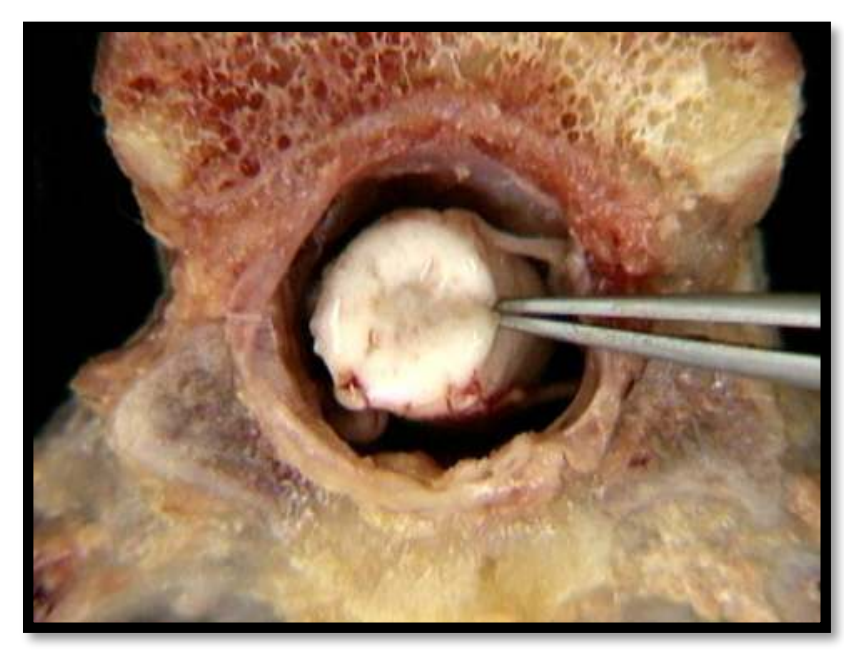

Prevalence $1 / 4,200 \quad(0.024 \%$ of immediate complications).

- Early diagnosis is important.

- Low diagnostic rate, retrospective diagnosis in many cases.

- It can also occur with caudal or paravertebral blockade of the brachial plexus in the interscalene approach.

Supportive therapy is important in case of consciousness, motor function and/or sympathetic tone depression.

CLINICAL MANIFESTATIONS Heterogeneous blockade.

- Sensitive blockade: large, asymmetrical, patched and cephalic progression; short duration. - Motor blockade: variable, limited, short duration.

Sympatholysis: Claude-Bernard-Horner syndrome, alterations of cranial nerves (II and IV). Cardiac arrest.

LUBENOW criteria, 1988 . Detection of $71 \%$ of the cases.

Diagnostic criteria: 2 major +1 minor.

- Major: negative aspiration of cerebrospinal fluid, extension of the disproportionate sensory block for the dose of LA administered.

- Minor: delay in the installation of the sensory/motor blockade in more than 10 minutes, variable motor blockade, exaggerated sympatholysis at the dose of LA administered.

DEFINITIVE DIAGNOSIS Radiological confirmation.

- Simple RX with contrast (injection of 0.4-0.5 ml) through epidural catheter: paraspinal image surrounding the spinal cord explained in the spinal ganglion. "Railroad rails".

- CT scan.

- NMR.

\section{LEARNING POINTS}

1- SB is heterogeneous, an if it is not suspected it will not be diagnosed.

2- Clinical suspicion with radiological definitive diagnosis.

3- If suspected, we should limit de LA dose and prepare general anesthesia for patient safety.

4- Do not confuse SB with total spinal blockade.

5- It is important to check the patient some days after the puncture to monitor possible complications in subsequent days.
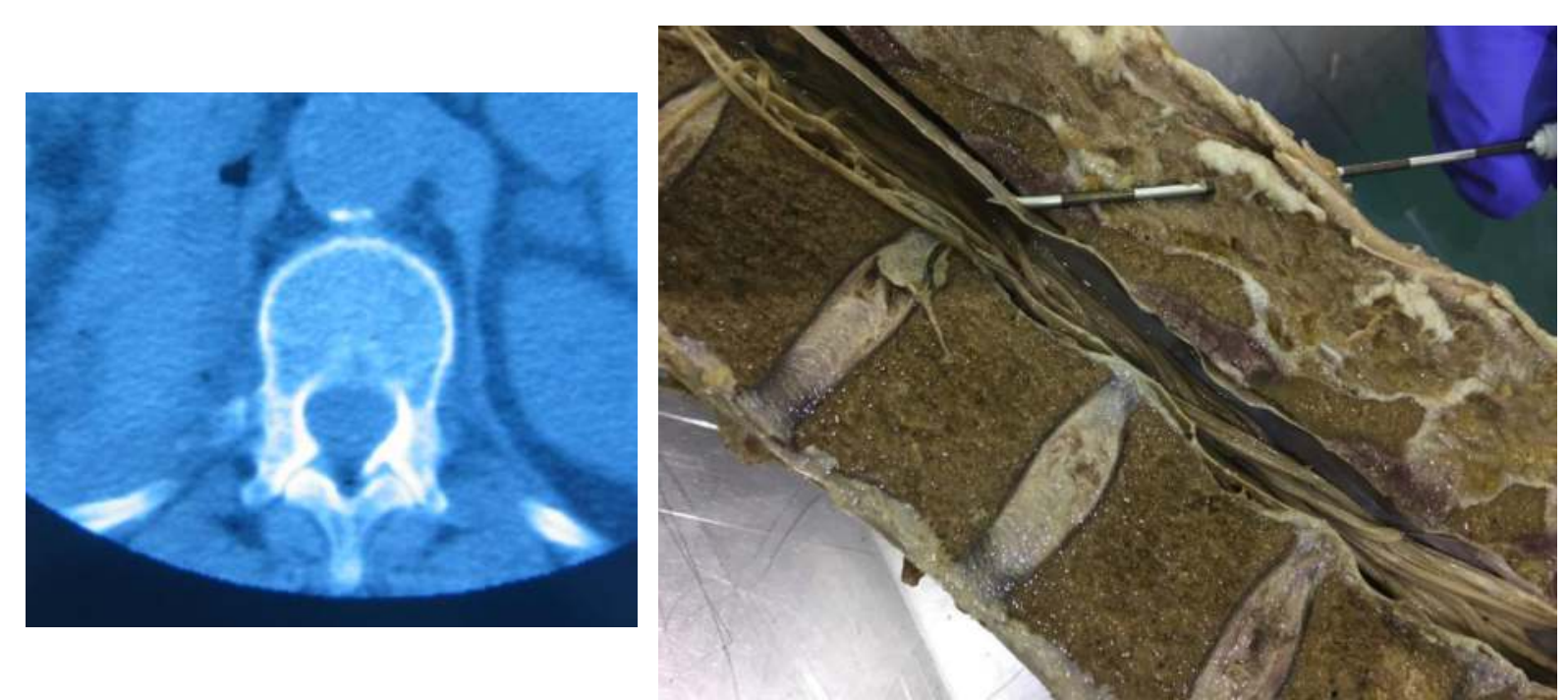

\section{REFERENCES}

1. Rev Esp Anestesiol Reanim. 2008 Nov;55(9):552-62. Complications after regional anesthesia. Tornero Tornero JC, Gómez Gómez M, Fabregat Cid G, Aliaga Font L, Roqués Escolar V, Escamilla Cañete B, Guerrí Cebollada A.

2. Anesthesiol Clin. 2011 Jun;29(2):279-90. doi: 10.1016/j.anclin.2011.04.002. Epub 2011 May 5. Unintentional subdural injection: a complication of neuraxial anesthesia/analgesia. Hoftman N.

3. Reg Anesth Pain Med. 2009 Jan-Feb;34(1):12-6. doi: 10.1097/AAP.0b013e31819339cf. Diagnosis of unintentional subdural anesthesia/analgesia: analyzing radiographically proven cases to define the clinical entity and to develop a diagnostic algorithm. Hoftman NN, Ferrante FM.

4. Rev Esp Anestesiol Reanim. 1999 Mar;46(3):126-9. Accidental catheterization of the subdural space. Confirmation by radiological study. Tornero JC, Vila Senante M, Comallonga Comallonga N, Arén Frontera JJ. 